\title{
Postoperative abdominal adhesions and their prevention in gynaecological surgery. Expert consensus position
}

\author{
Rudy Leon DeWilde • Geoffrey Trew • \\ on behalf of the Expert Adhesions Working Party \\ of the European Society of Gynaecological Endoscopy \\ (ESGE)
}

Received: 11 April 2007 / Accepted: 12 July 2007 / Published online: 3 August 2007

(C) Springer-Verlag 2007

\begin{abstract}
Adhesions are the most frequent complication of abdominopelvic surgery, yet many surgeons are still not aware of the extent of the problem and its serious consequences. While adhesions may cause few or no detrimental effects to patients, in a considerable proportion of cases there are major short- and long-term consequences, including small-bowel obstruction, infertility and chronic pelvic pain. Adhesions complicate future surgery with important associated morbidity and expense - and a considerable risk of mortality. Despite advances in surgical techniques in recent years, the burden of adhesion-related complications has not changed. Adhesions should now be considered the most common complication of abdominopelvic surgery. Adhesiolysis remains the main treatment, despite the fact that adhesions reform in most patients. Developments in adhesion-reduction strategies and new agents now offer a realistic possibility of reducing the risk of adhesions forming and can improve the outcomes for patients and the associated onward burden. This consensus position represents the collective views of 35 gynaecologists with a recognised interest in adhesions. The position is presented in two parts. The first part reviews the published literature on the extent of the problem of adhesions, and the
\end{abstract}

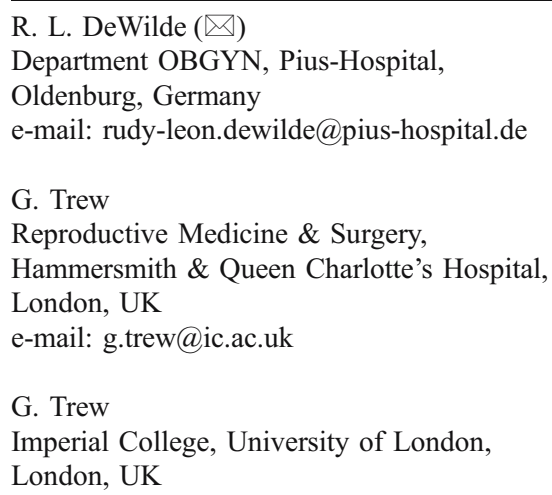

second part considers the opportunities to reduce their incidence. It also provides collective proposals on the actions that European gynaecologists should take to avoid causing adhesions. Importantly it also advises that it is now time to inform patients of the risks associated with adhesion-related complications during the consent process. With increasing evidence to support the efficacy of adhesion-reduction agents to complement good surgical practice, all surgeons should act now to reduce adhesions and fulfil their duty of care to patients.

Keywords Adhesions · Adhesiolysis · Guidelines · Gynaecology · Surgery

\section{Introduction}

Adhesions are the most frequent complication of abdominal surgery and may represent one of the greatest unresolved medical problems in medicine today [1], yet many surgeons are still not aware of the extent of the problem and its serious consequences.

Sixty to $90 \%$ of patients who have undergone major gynaecological surgery will develop adhesions [2]. Adhesiolysis remains the main treatment, despite the fact that adhesions reform in most patients (mean 85\%) regardless of the method of adhesiolysis used or the type of adhesion being lysed [3].

While adhesions may cause few or no detrimental effects to patients, in a considerable proportion of cases there are serious short- and long-term consequences, with important associated morbidity and expense - and a considerable risk of mortality.

Recent epidemiological data have demonstrated the true extent of adhesion-related complications, and evidence is emerging on the level of associated risk for patients. 
Despite advances in surgical techniques in recent years, the burden of adhesion-related complications has not changed $[4,5]$. While laparoscopic procedures are commonly believed to be less adhesiogenic and cause fewer de novo adhesions to form compared to open surgery $[6,7]$, for many procedures, the comparative risk of adhesion-related complications following open and laparoscopic gynaecological surgery is similar [5].

Developments in adhesion-reduction strategies and new agents do, however, now offer a realistic possibility of reducing the risk of adhesions forming and thus may improve the outcomes for patients and the associated onward burden. The importance of providing clear recommendations on adhesions and their prevention following gynaecological surgery is very apparent.

For this reason, and following recent reviews by colleagues in the United Kingdom [8] and Germany [9], an Expert Working Party under the auspices of the 15th Annual Congress of the European Society of Gynaecological Endoscopy (ESGE) was convened to increase awareness and offer practical proposals to minimise the problem.

The project, while conceived by two of us (RDW, GT), involved a Working Party of 35 gynaecologists with a recognised interest in adhesions (see Appendix), all of whom contributed actively to the development of this paper through reviews, inputs and consensus proposals, with the majority also attending the consensus workshop held during the 15th Annual Congress of the ESGE. The project progressed in accordance with accepted processes for the development of consensus statements (see "Consensus process including conflict of interest").

The project is presented in two parts. The first as published here, provides an overview of the published literature on the extent of the problem of adhesions. The second appears in the next issue of Gynecological Surgery and considers the opportunities to reduce the problems of adhesions. Consensus proposals on the actions that European gynaecologists should now take are also provided in part 2. These proposals are collective opinion and should not be used for performance measure or competency purposes. Together these two papers provide a collective consensus position which it is hoped will raise the level of awareness and understanding of adhesions, and the associated health-care burden and costs, thereby encouraging heightened discussions and actions to address this area of unmet need.

\section{History}

Adhesions have been the subject of research for many years with the first case of fatal adhesion-related intestinal obstruction reported as far back as 1872 [10]. Despite considerable research into adhesions through the years, resulting in improvements in surgical techniques and the use of powder-free surgical gloves, the problem remains as most surgeons are still not fully aware of the magnitude and consequences of adhesions. This lack of awareness has been cited by Ellis as the greatest impediment to reducing adhesion formation, which he aptly described as 'a sense of fatalism affecting the surgical community, akin to the attitude of surgeons to wound infection in the days before Lister' [11].

\section{The epidemiology and clinical importance of adhesions}

There is strong evidence that the real extent of adhesions and adhesion-related complications is underestimated by most surgeons for the following reasons:

- Adhesive complications occur unpredictably, often many years after a procedure.

- The complications are often treated by physicians or specialists other than the initial operating surgeon.

- The aetiology of adhesion formation is still incompletely understood.

- There has been a long track record of failure or limited use of traditional adhesion-prevention strategies, until the recent introduction of newer agents.

- Although adhesions can be present, they may be asymptomatic so they remain undiagnosed in most cases.

Following initial practice-based research [12-15], the Surgical and Clinical Adhesions Research (SCAR) group has quantified the epidemiology and burden that adhesions pose to patients, surgeons and health services. The initial study followed up adhesion-related hospital readmissions in Scotland for 10 years in a cohort of patients undergoing open abdominal or pelvic surgery [16]. The SCAR Group found that over the study period, up to one in three patients were readmitted at least twice for adhesion-related problems (or other surgery potentially complicated by adhesions) and, moreover, the readmissions continued steadily throughout the 10 years. This research also indicated that patients undergoing open surgical procedures on the colon and rectum [17] and on the fallopian tubes, ovaries and uterus [4] were at most risk of adhesion-related readmissions. The SCAR group subsequently reported that for therapeutic and diagnostic laparoscopic procedures (i.e. all laparoscopic procedures undertaken with the exception of low-risk tubal sterilisations), the risk of adhesion-related readmission was comparable to that of gynaecological laparotomy [5]. The group concluded that despite advances in surgical technique, the burden of adhesion-related readmissions continues. 
Other studies report that the incidence of adhesions following gynaecological laparoscopic surgery is $70-100 \%$, diagnosed by second-look analysis [18, 19]. Laparoscopic surgery is generally considered to be accompanied by reduced de novo adhesion formation in comparison to laparotomy [19-21], while reformation is similar. However, a meta-analysis revealed comparable results for open versus laparoscopic surgery for both formation of de novo adhesions and reformation following adhesiolysis [22]. It is postulated that the environment of the pneumoperitoneum [23] and the surgeon's training may also play an important role in the incidence of adhesions [24].

\section{Pathogenesis of adhesions}

In simple terms, adhesions are abnormal attachments between tissues and organs [25] and may be congenital or acquired [26]. The development of acquired adhesions is a generalised phenomenon in response to trauma to the peritoneum. The trauma may be inflammatory or surgical, and may include exposure to infection or intestinal contents, ischaemia, irritation from foreign materials (such as sutures, gauze particles or, historically, glove powder), desiccation, or overheating by lamps or irrigation fluid [27].

The peritoneum is the most extensive serous membrane in the body, serving to minimise friction and facilitate free movement of abdominal viscera, to resist and localise infections and to store fat. It comprises a single-cell layer of mesothelium lying on a submesothelial connective tissue matrix which contains numerous capillaries and lymphatic channels which open into the mesothelial cell monolayer. The surface of the mesothelium is coated in phospholipid (Fig. 1).

This mesothelial monolayer is extremely delicate and hence susceptible to damage, although it also has excellent healing properties provided that there is no ongoing

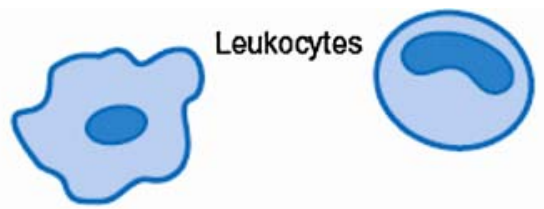

Phospholipids

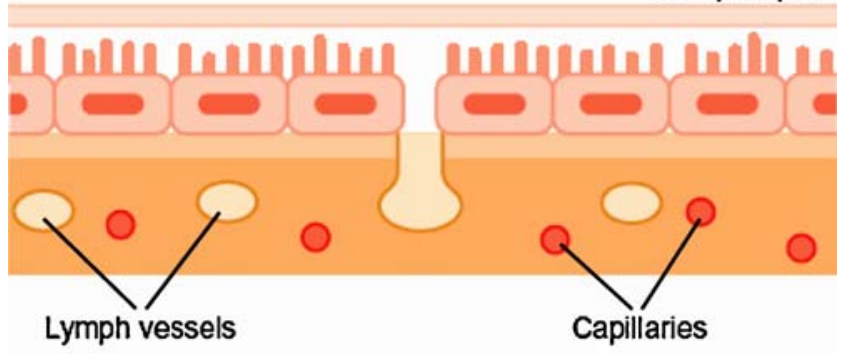

Fig. 1 Anatomy of the peritoneum inflammation which reduces fibrinolytic activity or deprives tissues of oxygen.

The pathogenesis of adhesion formation is complex, with many factors involved [28, 29] (Fig. 2).

Histopathological studies demonstrate a clear sequence of events from injury to the formation of adhesions. In general, abrasion and other trauma during surgery lead to the disruption of the peritoneal mesothelium and fibrin is then released along with a cascade of other elements, including leukocytes and mesothelial cells. The fibrin is

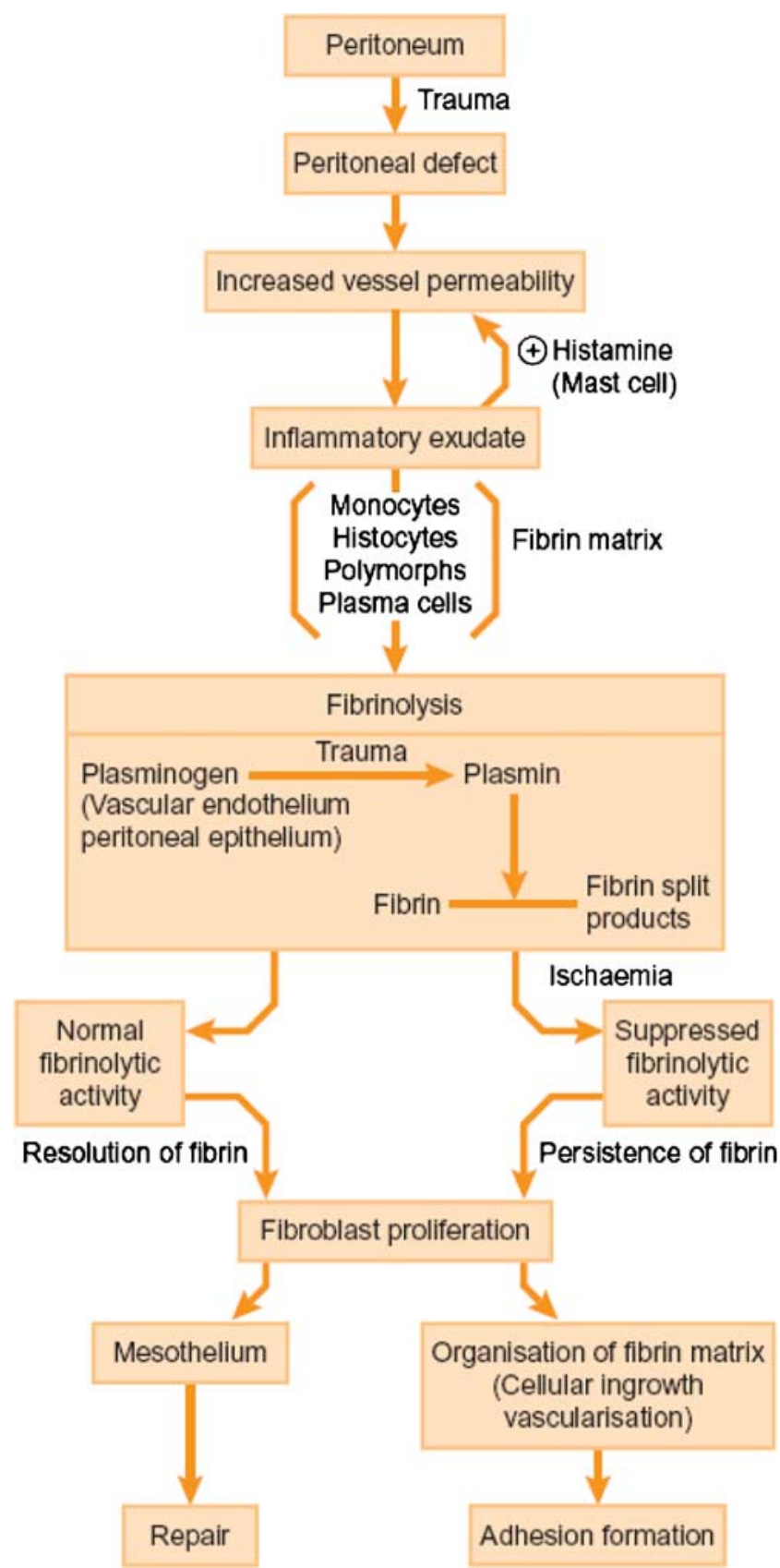

Fig. 2 Summary of normal tissue repair and adhesion formation following surgical trauma [28] 
deposited at the damaged surfaces as a result of bleeding and post-traumatic inflammation.

During wound healing, fibrin deposits from damaged mesothelium enlarge to form a bridge between opposing tissue surfaces. Locally generated fibrinolytic factors are released which may degrade all or part of this fibrin bridge. However, surgery, infection and hypoxia dramatically diminish fibrinolytic activity and, under these circumstances, fibroblasts and other cells may migrate across the bridge remnants transforming it into an adhesion [30] (Fig. 3).

The process of adhesion formation commences from the moment of peritoneal injury during surgery, as a result of which the inflammatory cascade is triggered. While the severity and extent of adhesions may change over weeks or months, the question of whether or not an adhesion develops at all is determined in the 3-5 days after peritoneal trauma takes place, i.e. after surgery has been carried out [31]. It is during this post-surgical period that the fibrin layer is reduced through fibrinolysis and the peritoneal membrane either becomes fully re-epithelialised or not. If fibrinolysis does not occur, an irreversible tissue bridge (adhesion) develops, which strengthens within the following weeks and months and in which blood vessels and nerve fibres may form [32].

The interaction of the acute-phase inflammatory protein cascade is, however, not fully understood, nor is its role in changing gene expression patterns and regulating both normal and adhesion fibroblasts [1,33]. Adhesion formation is a multigenic phenomenon and the role of different activators and factors in this complex process is a matter of considerable research, aimed at not only improving our understanding of the development of adhesions, but also, most importantly, finding optimal strategies for adhesion prevention [28, 29]. The most promising avenues of research are strategies to separate damaged peritoneal surfaces, the fostering of the process of fibrinolysis and

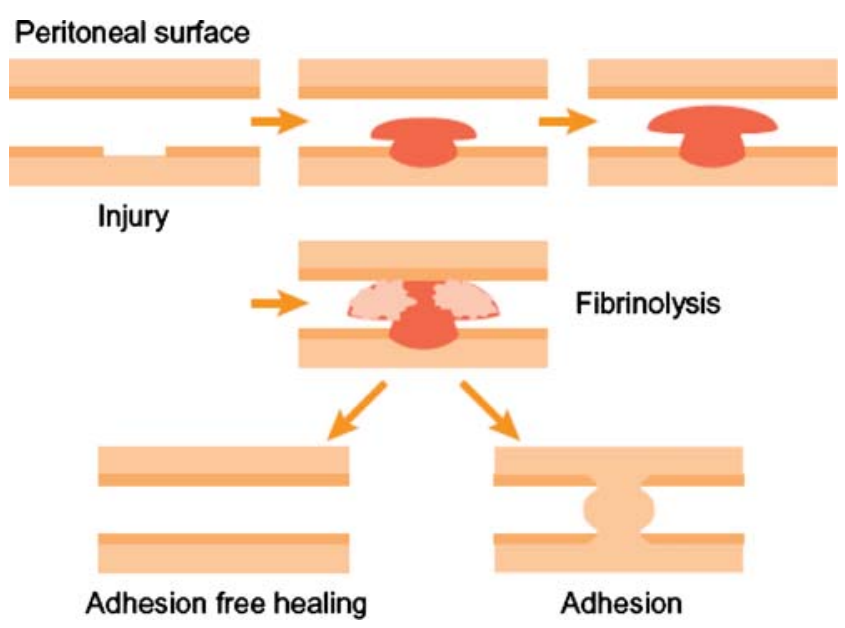

Fig. 3 Development of adhesions [30] the regulation of hypoxia and prevention of angiogenesis. While the latter approaches are currently still only a research hope, the former is already an available option that surgeons can consider using.

\section{Adhesion-related complications}

Although adhesions are now the most frequent complication of abdominopelvic surgery, it is not possible to identify which particular adhesions will cause complications.

The most frequent adhesion-related complications are secondary infertility in women $(20-40 \%$ of cases are caused by adhesions $[34,35])$ and small-bowel obstruction (74\% of cases are adhesion-related [36]). Adhesions are also thought to be a significant cause of chronic pelvic pain in many patients [27, 32, 37], but this relationship still requires further investigation. While most patients will develop adhesions following surgery [2], the majority will not experience these problems and may not be aware of their adhesions unless they have further surgery.

For patients undergoing subsequent surgery, adhesions pose an important complicating factor with adhesions from previous surgery significantly increasing operating time [38, 39]. In addition, even in the hands of experienced surgeons, there is a $19 \%$ risk of inadvertent enterotomy at reoperative laparotomy [40] and a $10-25 \%$ risk of bowel injury in laparoscopic adhesiolysis [41]. In medicolegal terms, tissue damage to underlying structures is the most common factor in successful surgical negligence suits [42]. The associated costs of adhesions to health services, patients and society are significant and continue to increase.

Infertility

Adhesions are the leading cause of secondary infertility in women. They affect fertility adversely by distorting adnexal anatomy and by interfering with gamete and embryo transport. They have been shown to cause peritoneal infertility in $15-20 \%$ of women [34, 35, 43]. Furthermore, tubal-related problems account for up to $40 \%$ of female infertility cases, with identifiable causes including postinfectious, endometriosis-related and post-surgical adhesion formation [44, 45].

While infertility often has multifactorial causes, there is a clear-cut correlation between adhesions and infertility. In women with infertility as a result of adnexal adhesions, pregnancy rates of 32 and $45 \%$ at 12 and 24 months respectively have been reported following adhesiolysis, compared with 11 and $16 \%$ at corresponding time intervals in untreated women [46]. A follow-up period of 3 years reported higher pregnancy rates in women who underwent tubal surgery compared with those who did not (29 vs $12 \%$ ) 
[47]. In women followed for an average 49 months after tubal surgery, term pregnancy rates correlated with adhesion scores as assigned using the American Fertility Society classification for adnexal adhesions [48].

\section{Small-bowel obstruction}

In the treatment of adhesion-related small-bowel obstruction, outcomes following medical management have been shown to be worse if the adhesions resulted from previous appendicectomy or tubal or ovarian surgery [49].

Small-bowel obstruction (SBO) is the most serious adhesion-related complication with a $10 \%$ risk of mortality [50] if not diagnosed and treated immediately. While the risk of SBO is highest after colorectal surgery, it is also a significant problem following gynaecological surgery. In the SCAR study, $4.5 \%$ of readmissions following gynaecological laparotomy were for SBO [16].

A recent retrospective analysis of all SBO admissions in two hospitals during the period January 1998 to December 2005 showed that in non-oncological cases, $50.4 \%$ of admissions were the result of previous gynaecological surgery with total abdominal hysterectomy cited as the most common cause of SBO [51]. In this study, a total of 13.6 cases per 1,000 resulted in SBO, $75 \%$ of these being diagnosed as complete SBO.

This work also suggested that laparoscopic hysterectomy and other procedures did not carry such a high risk of SBO, but the numbers of laparoscopic procedures were more limited. This recent study supports previous findings highlighting the important risk of SBO following gynaecological laparotomy [2, 49, 52-57].

\section{Chronic pelvic pain}

A relationship between adhesions and pelvic pain, although controversial, is also apparent. An analysis of 11 studies involving a total of almost 1,000 patients suffering from pelvic pain demonstrated adhesions as being the most common associated pathology in $40 \%$ of cases [32].

However, the pathophysiological connection between adhesions and pain remains unclear. It is uncertain which mechanisms trigger adhesion-related pain under physiological conditions, but nerve fibres are often present in adhesions $[58,59]$ and may be involved in the aetiology. Patients have been shown to experience pain when adhesions are touched [60], and this observation has been further supported in various pain-mapping studies [61, 62].

Whether or not adhesiolysis provides an improvement in chronic pelvic pain is uncertain. While retrospective and prospective studies have shown improvement in $50-90 \%$ of cases after laparoscopic adhesiolysis [63-68], only very few studies fulfilled the conditions of a controlled or even prospective randomised design. In randomised studies, the evidence is more ambiguous, and it is unclear if adhesiolysis is a successful treatment option in the majority of women [41, 69]. As there is a known high rate of reformation of adhesions following surgery (mean reformation rate of $85 \%$ ) regardless of the method of adhesiolysis [3], and as chronic pain may have multifactorial causes, e.g. psychosomatic, it is not surprising that the role of adhesiolysis as a treatment for chronic pain is uncertain. The risk of intestinal perforation that occurs during laparoscopic procedures for symptomatic adhesions is also high-reported as up to $25 \%$ of patients [41, 70]. In a recent review, van der Wal and colleagues noted that considering the risk of complications associated with laparoscopic adhesiolysis, it should no longer be recommended as a therapy for adhesion-related chronic abdominal pain [70]. A critical analysis of the existing literature is therefore needed to further assess the therapeutic effect of adhesiolysis in patients with pelvic pain.

\section{The cost of adhesions}

Pre-existing adhesions significantly prolong the duration of surgery $[38,39]$ and lead to considerable complications in an important percentage of patients. This is particularly the case in accidental intestinal enterotomy which is accompanied by an increased need for intensive care facilities, extended hospitalisation and increased ward costs [40, 41].

A survey in 1993 in Sweden - a country with a population of some 7.1 million - found that total care costs (including costs for sick leave) for adhesive SBO amounted to at least $€ 10$ million per year (US\$13 million) [71]. The costs of all hospitalisations for adhesiolysis in the United States in 1994 were estimated to be around $€ 1$ billion (US $\$ 1.33$ billion), of which approximately $€ 596$ million (US $\$ 764$ million) was for hospitalisations directly attributable to adhesions [72].

Using the SCAR data $[16,17]$, the average length of hospital stays for adhesion-related general and gynaecological surgery in 1994 showed that treatment costs for adhesion-related surgical procedures in Scotland represented $2 \%$ of expenditure on hospital and community sector services in that year [73], being over $£ 6$ million ( €9 million). This was a conservative estimate of the true costs. A subsequent cost model developed by Wilson and co-workers based on the SCAR data predicted that the direct annual cost of adhesion-related readmissions for the United Kingdom as a whole within the first year after initial lower abdominal surgery would be in excess of approximately $€ 36$ million ( $£ 24.2$ million), rising to $€ 141$ million (£95.2 million) in the 10th year after surgery [74]. Wilson et al. estimated that the cumulative year-on-year direct costs 
of adhesion-related readmissions for a 10-year period would be more than $€ 843$ million ( $£ 569$ million) in the UK population (approximately 58 million in 1999).

Extrapolation of these cost data across Europe or on a global scale indicates the extent of the problem of adhesionrelated complications and highlights the concern that adhesion-related events represent a huge burden for health-care resources and funding.

In part 2, the opportunities to reduce the burden of adhesions are reviewed and consensus proposals on action for European gynaecologists to take are presented.

Acknowledgements The consensus project and manuscript development were facilitated by Corvus Communications Limited under the direction of Rudy DeWilde and Geoffrey Trew. Special thanks for the work of Alison Crowe, Alastair Knight and Jill Kirkdale in patiently supporting and encouraging all Adhesions Working Party members to actively contribute and provide feedback on all stages of the project development.

\section{Appendix}

Expert Adhesions Working Party of the ESGE

Members of the Expert Adhesions Working Party of the European Society of Gynaecological Endoscopy (ESGE) are listed below alphabetically. All members actively contributed to the development and review of the consensus paper recognising the importance of publishing on a matter of such importance. The majority participated at the Adhesions Consensus Expert Workshop convened during the 15th Annual Congress of the ESGE and the project progressed in accordance with accepted processes for the development of consensus statements (see "Consensus process including conflict of interest").

Prof Rudy Leon DeWilde, Pius Hospital, Oldenburg, Germany

Mr Geoffrey Trew, Hammersmith Hospital, London, UK

Dr Stefano Angioni, H San Giovanni di Dio, Cagliari, Italy

Prof Alain Audebert, Rue de Turenne, Bordeaux, France

Prof Pedro Barri, Institut Universitari Dexeus, Barcelona, Spain

Prof Charles Chapron, Clinique Universitaire Baudeloque, Paris, France

Prof Maria Elisabetta Coccia, Ospedale di Careggi, Florence Italy

Prof Michel Degueldre, Centre Hospitalier Universitaire St-Pierre, Brussels, Belgium

Prof Gere diZerega, Keck School of Medicine, University of Southern California, Los Angeles, CA, USA

Prof Enrique Garcia, Instituto Valenciano de Oncologia, Valencia, Spain
Dr Robert J S Hawthorn, Southern General Hospital, Glasgow, Scotland

Dr Petra Janssen, Klinikum Konstanz, Konstanz, Germany

Prof Philippe R Koninckx, University Hospital Gasthuisberg, Leuven, Belgium

Prof Matthias Korell, Klinikum Duisburg, Wedau Kliniken, Duisburg, Germany

Dr Stefano Landi, Ospedale Sacro Cuore, Verona, Italy Mr Adrian M Lower, The London Clinic, London, UK

Prof Per Lundorff, Kvindeafdelingen, Viborg Sygehus, Denmark

Dr Enda McVeigh, John Radcliffe Hospital, Oxford, UK Prof Patrick Madelenat, Hôpital Bichat, Paris, France

Prof Valerio Mais, H San Giovanni di Dio, Cagliari, Italy

Prof Gian Benedetto Melis, H San Giovanni di Dio, Cagliari, Italy

Prof Luca Minelli, Ospedale Sacro Cuore, Verona, Italy

Prof Carmine Nappi, Università degli studi di Napoli

Federico II, Naples, Italy

Prof Michelle Nisolle, University of Liege, Liege, Belgium

Prof George Pados, Interbalkan European Medical Center (Diavalkanino), Thessaloniki, Greece

Prof George Pistofidis, AKESO, Gynaecology \& Reproductive Centre, Athens, Greece

Dr Massimillano Pellicano, Università degli studi di Napoli Federico II, Naples, Italy

Prof Jean Luc Pouly, Polyclinique de l'Hôtel-Dieu, Clermont-Ferrand, France

Prof Stefan Rimbach, Klinikum Konstanz, Konstanz, Germany

Prof Ernst Schmidt, Diakonie-Krankenhaus $\mathrm{GmbH}$ (Frauenklinik), Bremen, Germany

Prof Christopher Sutton, The Guildford Nuffield Hospital, Guildford, UK

Dr Alicia Ubeda, Institut Universitari Dexeus, Barcelona, Spain

Prof Diethelm Wallwiener, Universitäts-Frauenklinik Tübingen, Tübingen, Germany

Prof Arnaud Wattiez, IRCAD (Institut de Recherche contre les Cancers de l'Appareil Digestif), Hôpitaux Universitaires, Strasbourg, France

Prof Errico Zupi, S. Giovanni calibita Fatebenefratelli Isola Tiberina, Rome, Italy

Consensus process including conflict of interest

The project processes were in accordance with the ACCP Definition of Consensus Statement [75].

In agreement with the President and the International Scientific Committee of the European Society of Gynaecological Endoscopy (ESGE), an Adhesions Consensus 
Expert Working Party was convened during the 15th Annual Congress of the ESGE.

Invitations to join the Expert Working Party were issued to colleagues who were known to have interest and published expertise in the field. No one declined to be involved.

Funding for the expenses of Working Party members to meet at ESGE and to provide input into the research, writing and manuscript review process was sought from companies with a known interest in adhesions in Europe (Genzyme, Confluent, Gynaecare, Baxter BioSurgery). Of these, only Baxter BioSurgery agreed to provide funding and the company provided an unconditional educational grant to support the work. Baxter BioSurgery has had no input to the Working Party consensus process or the proposals made. While it has had the opportunity to review the manuscript, it has at all stages declined to comment on it. The evidence and scope of the manuscript were reviewed and commented on by the Working Party in preparation for and during a workshop at ESGE. Collective consensus opinion was agreed at the workshop and presented during plenary session to seek wider input. In formalising the consensus and this paper, all work has been reviewed and formally agreed upon by all Working Party members.

\section{References}

1. Diamond MP, El-Hammady E, Wang R, Kruger M, Saed G (2004) Regulation of expression of tissue plasminogen activator and plasminogen activator inhibitor-1 by dichloroacetic acid in human fibroblasts from normal peritoneum and adhesions. Am J Obstet Gynecol 190:926-934

2. Monk BJ, Berman ML, Monitz FJ (1994) Adhesions after extensive gynecologic surgery: clinical significance, etiology and prevention. Am J Obstet Gynecol 170:1396-1403

3. Diamond MP, Freeman ML (2001) Clinical implications of postsurgical adhesions. Hum Reprod Update 7:567-576

4. Lower AM, Hawthorn RJS, Ellis H, O'Brien F, Buchan S et al (2000) The impact of adhesions on hospital readmissions over ten years after 8489 open gynecological operations: an assessment from the Surgical and Clinical Adhesions Research Study. Br J Obstet Gynaecol 107:855-862

5. Lower AM, Hawthorn RJS, Clark D, Boyd JH, Finlayson AR et al (2004) Adhesion-related readmissions following gynaecological laparoscopy or laparotomy in Scotland: an epidemiological study of 24,046 patients. Hum Reprod 19:1877-1885

6. Diamond MP, Daniell JF, Feste J, Surrey MW, McLaughlin DS et al (1987) Adhesion reformation and de novo adhesion formation after reproductive pelvic surgery. Fertil Steril 47:864-866

7. Pados G, Devroey P (1992) Adhesions. Curr Opin Obstet Gynecol $4: 412-418$

8. Trew G, Lower A (2004) Consensus in adhesion reduction management. The Obstetrician \& Gynaecologist 6:1-16

9. Rimbach S, Korell M, Tinneberg HR, DeWilde RL (2004) Adhesions and their prevention in gynaecologic surgery: current status and consensus based on four workshops. Geburtsh Frauenheilk 64:891-899
10. Bryant T (1872) Clinical lectures on intestinal obstruction. Med Tim Gaz 1:363-365

11. Ellis H (1998) The magnitude of adhesion related problems. Ann Chir Gynaecol 87:9-11

12. Menzies D, Ellis H (1990) Intestinal obstruction from adhesions how big is the problem? Ann R Coll Surg Engl 72:60-63

13. Ellis H (1983) Prevention and treatment of adhesions. Infect Surg $11: 803-817$

14. Menzies D (1992) Peritoneal adhesions. Incidence cause and prevention. Surg Annu 24(Part 1):27-45

15. Holmdahl L, Risberg B (1997) Adhesions: prevention and complications in general surgery. Eur J Surg 163:169-174

16. Ellis H, Moran BJ, Thompson JN, Parker MC, Wilson MS et al (1999) Adhesion-related hospital readmissions after abdominal and pelvic surgery: a retrospective cohort study. Lancet 353:14761480

17. Parker MC, Ellis H, Moran BJ, Thompson JN, Wilson MS et al (2001) Postoperative adhesions: ten-year follow-up of 12,584 patients undergoing lower abdominal surgery. Dis Colon Rectum 44:822-830

18. Canis M, Chapron C, Mage G, Pouly JL, Wattiez A et al (1992) Second-look laparoscopy after laparoscopic cystectomy of large ovarian endometriomas. Fertil Steril 58:617-619

19. Operative Laparoscopy Study Group (1991) Postoperative adhesion development after operative laparoscopy: evaluation at early second-look procedures. Fertil Steril 55:700-704

20. Lundorff P, Hahlin M, Källfelt B, Thorburn J, Lindblom B (1991) Adhesion formation after laparoscopic surgery in tubal pregnancy: a randomized trial versus laparotomy. Fertil Steril 55:911-915

21. Nezhat CR, Nezhat FR, Metzger DA, Luciano AA (1990) Adhesion reformation after reproductive surgery by videolaseroscopy. Fertil Steril 53:1008-1011

22. Wiseman DM, Trout JR, Diamond MP (1998) The rates of adhesion development and the effects of crystalloid solutions on adhesion development in pelvic surgery. Fertil Steril 70:702-711

23. Binda MM, Molinas CR, Koninckx PR (2003) Reactive oxygen species and adhesion formation. Clinical implications in adhesion prevention. Hum Reprod 18:2503-2507

24. Luciano A (1984) Laparotomy vs laparoscopy. In: diZerega GD (ed) Treatment of post surgical adhesions, progress in clinical and biological research, vol 358. Wiley-Liss, New York, pp 35-44

25. Wiseman D (1994) Polymers for the prevention of surgical adhesions. In: Domb AJ (ed) Polymeric site-specific pharmacotherapy. Wiley, New York, pp 370-421

26. Ellis $H$ (1982) The causes and prevention of intestinal adhesions. Br J Surg 69:241-243

27. Holmdahl L, Risberg B, Beck DE, Burns JW, Chegini $\mathrm{N}$ et al (1997) Adhesions: pathogenesis and prevention - panel discussion and summary. Eur J Surg 163:56-62

28. diZerega GS (2000) Peritoneum, peritoneal healing, and adhesion formation In: diZerega GS (ed) Peritoneal surgery. SpringerVerlag, New York, pp 3-37

29. Molinas CR, Binda MM, Koninckx PR (2006) Angiogenic factors in peritoneal adhesion formation. Gynecol Surg 3:157-167

30. Holmdahl L (1999) Making and covering surgical footprints. Lancet 353:1456-1457

31. Harris ES, Morgan RF, Rodeheaver GT (1995) Analysis of the kinetics of peritoneal adhesion formation in the rat and evaluation of potential antiadhesive agents. Surgery 117:663-669

32. diZerega GS (1997) Biochemical events in peritoneal tissue repair. Eur J Surg 577(Suppl):10-16

33. Rout UK, Saed GM, Diamond MP (2005) Expression pattern and regulation of genes differ between fibroblasts of adhesion and normal human peritoneum. Reprod Biol Endocrinol. DOI 10.1186/ 1477782731 
34. Hershlag A, Diamond MP, DeCherney AH (1991) Adhesiolysis. Clin Obstet Gynaecol 34:395-402

35. Mishell DR, Davajan V (1991) Evaluation of the infertile couple. In: Mishell DR Jr, Davajan V, Lobo RA (eds) Infertility contraception and reproductive endocrinology, 3rd edn. Blackwell Scientific, Boston, pp 557-570

36. Menzies D (1993) Postoperative adhesions: their treatment and relevance in clinical practice. Ann R Coll Surg Engl 75:147-153

37. Rapkin AJ (1986) Adhesions and pelvic pain: a retrospective study. Obstet Gynaecol 68:13-15

38. Coleman MG, McLain AD, Moran BJ (2000) Impact of previous surgery on time taken for incision and division of adhesions during laparotomy. Dis Colon Rectum 43:1297-1299

39. Beck DE, Ferguson MA, Opelka FG, Fleshman JW, Gervaz P et al (2000) Effect of previous surgery on abdominal opening time. Dis Colon Rectum 43:1749-1753

40. van der Krabben AA, Dijkstra FR, Nieuwenhuijzen M, Reijnen MMPJ, Schaapveld M et al (2000) Morbidity and mortality of inadvertent enterotomy during adhesiotomy. Br J Surg 87:467-471

41. Swank DJ, Swank-Bordewijk SC, Hop WC, van Erp WF, Janssen IM et al (2003) Laparoscopic adhesiolysis in patients with chronic abdominal pain: a blinded randomised controlled multi-centre trial. Lancet 361:1247-1251

42. Pownall M (1999) Tissue damage is commonest cause of surgical negligence suits. BMJ 318:692

43. Marana R, Muzii L (2000) Infertility and adhesions. In: diZerega GS (ed) Peritoneal surgery. Springer-Verlag, New York, pp 329-333

44. Canis M, Mage G, Pouly JL, Manhes H, Wattiez A et al (1991) Laparoscopic distal tuboplasty: report of 87 cases and a 4-year experience. Fertil Steril 54:616-621

45. Posaci C, Camus M, Osmanagaoglu K, Devroey P (1999) Tubal surgery in the era of assisted reproduction technology. Clinical options. Hum Reprod 14(Suppl 1):120-136

46. Tulandi T, Collins JA, Burrows E, Jarrell JF, McInnes RA et al (1990) Treatment-dependent and treatment-independent pregnancy among women with periadnexal adhesions. Am J Obstet Gynecol 162:354-357

47. $\mathrm{Wu} \mathrm{CH}$, Gocial B (1988) A pelvic scoring system for infertility surgery. Int J Fertil 33:341-346

48. Marana R, Rizzi M, Muzii L, Catalano GF, Caruana P et al (1995) Correlation between the American Fertility Society classifications of adnexal adhesions and distal tubal occlusion, salpingoscopy, and reproductive outcome in tubal surgery. Fertil Steril 64:924929

49. Meagher AP, Moller C, Hoffmann DC (1993) Non-operative treatment of small bowel obstruction following appendicectomy or operation on the ovary or tube. Br J Surg 80:1310-1311

50. Menzies D, Parker M, Hoare R, Knight A (2001) Small bowel obstruction due to postoperative adhesions: treatment patterns and associated costs in 110 hospital admissions. Ann R Coll Surg Engl 83:40-46

51. Al-Sunaidi M, Tulandi T (2006) Adhesion-related bowel obstruction after hysterectomy for benign conditions. Obstet Gynecol 108:1162-1166

52. Al-Took S, Platt R, Tulandi T (1999) Adhesion-related smallbowel obstruction after gynecologic operations. Am J Obstet Gynecol 180:313-315

53. Cox MR, Gunn IF, Eastman MC, Hunt RF, Heinz AW (1993) The operative aetiology and types of adhesions causing small bowel obstruction. Aust NZ J Surg 63:848-852

54. Melody GF (1958) Intestinal obstruction following gynecologic surgery. Obstet Gynecol 11:139-147
55. Krebs HB, Goplerud DR (1987) Mechanical intestinal obstruction in patients with gynecologic disease: a review of 368 patients. Am J Obstet Gynecol 157:577-583

56. Soo KC, Davidson T, Parker M, Paterson I, Paterson A (1988) Intestinal obstruction in patients with gynaecological malignancies. Ann Acad Med Singapore 17:72-75

57. Johnson N, Barlow D, Lethaby A, Tavender E, Curr E et al (2006) Surgical approach to hysterectomy for benign gynaecological disease (review). Cochrane Database Syst Rev. DOI 10.1002/14651858

58. Tulandi T, Chen MF, Al-Took S, Watkin K (1998) A study of nerve fibers and histopathology of postsurgical, postinfectious, and endometriosis-related adhesions. Obstet Gynecol 92:766-768

59. Sulaiman H, Gabella G, Davis C, Mutsaers SE, Boulos P et al (2001) Presence and distribution of sensory nerve fibers in human peritoneal adhesions. Ann Surg 234:256-261

60. Almeida OD, Val-Gallas JM (1997) Conscious pain mapping. J Am Assoc Gynecol Laparosc 4:587-590

61. Demco L (2004) Pain mapping of adhesions. J Am Assoc Gynecol Laparosc 11:181-183

62. Demco LA (2000) Pain referral patterns in the pelvis. J Am Assoc Gynecol Laparosc 7:181-183

63. Howard FM (1993) The role of laparoscopy in chronic pelvic pain: promise and pitfalls. Obstet Gynecol Surv 48:357-387

64. Ford JC, English J, Giannopoulos T (2003) Long-term follow up of pain and quality of life scores after laparoscopic adhesiolysis. Rev Gyn Pract 3(Suppl):abstract 001

65. Malik E, Berg C, Meyhöfer-Malik A, Haider S, Rossmanith WG (2000) Subjective evaluation of the therapeutic value of laparoscopic adhesiolysis: a retrospective analysis. Surg Endosc 14:79-81

66. Nezhat FR, Crystal RA, Nezhat CH, Nezhat CR (2000) Laparoscopic adhesiolysis and relief of chronic pelvic pain. JSLS $4: 281-285$

67. Saravelos HG, Li TC, Cooke ID (1995) An analysis of the outcome of microsurgical and laparoscopic adhesiolysis for chronic pelvic pain. Hum Reprod 10:2895-2901

68. Swank DJ, van Erp WFM, Repelaer van Driel OJ, Hop WCJ, Bonjer HJ et al (2003) A prospective analysis of predictive factors on the results of laparoscopic adhesiolysis in patients with chronic abdominal pain. Surg Laparosc Endosc Percutan Tech 13:88-94

69. Peters AAW, Trimbos-Kemper GCM, Admiraal C, Trimbos JB, Hermans J (1992) A randomised clinical trial on the benefit of adhesiolysis in patients with intraperitoneal adhesions and chronic pelvic pain. Br J Obstet Gynaecol 99:59-62

70. Van der Wal JBC, Halm JA, Jeekel J (2006) Chronic abdominal pain: the role of adhesions and benefit of laparoscopic adhesiolysis. Gynecol Surg 3:168-174

71. Ivarsson ML, Holmdahl L, Franzen G, Risberg B (1997) Cost of bowel obstruction resulting from adhesions. Eur J Surg 163:679-684

72. Fox Ray N, Denton WG, Thamer M, Henderson SC, Perry S (1998) Abdominal adhesiolysis: inpatient care and expenditures in the United States in 1994. J Am Coll Surg 186:1-9

73. Parker MC on behalf of the SCAR Study Steering Group (1999) The economic and practical implications of adhesive small bowel disease. ASCRS and Tripartite Meeting Adhesions Symposium, Washington DC, USA

74. Wilson MS, Menzies D, Knight AD, Crowe AM (2002) Demonstrating the clinical and cost effectiveness of adhesion reduction strategies. Colorectal Dis 4:355-360

75. American College of Chest Physicians (2007) Definitions of ACCP evidence-based guidelines, consensus statements, and other reviews and projects. http://www.chestnet.org/education/guide lines/definitions.php. (Cited 2 Jul 2007) 